\title{
Chronic Necrotizing Pulmonary Aspergillosis in a Patient with Non-Small Cell Lung Carcinoma Following Radiotherapy
}

Ege Gulec Balbay ${ }^{\star}$, Yagmur Bahar, Sinem Berik and Ali Nihat Annakkaya

Department of Chest Diseases, Faculty of Medicine, Duzce University, Turkey

*Corresponding author: Ege Gulec Balbay, Department of Chest Diseases, Faculty of Medicine, Duzce University, Turkey, Tel: 0380 542 11 11; E-mail: egegulecbalbay@gmail.com

Rec date: Dec 12, 2013, Acc date: Apr 24, 2014, Pub date: Apr 26, 2014

Copyright: ( 2014 Balbay EG, et al. This is an open-access article distributed under the terms of the Creative Commons Attribution License, which permits unrestricted use, distribution, and reproduction in any medium, provided the original author and source are credited

\begin{abstract}
Chronic necrotizing pulmonary aspergillosis is characterized by a pulmonary infiltration with cavitation in patients with chronic pulmonary disease, slight immunodeficiency or healthy patients. A 57-year-old man with non-small cell carcinoma who has had radiotherapy was admitted with a history of left side pleuritic chest pain, non-productive cough, fever and dyspnea. Aspergillus fumigatus was found in his mycological exams of BAL fluid. Serum examination presented positive galactomannan. Final diagnosis was semi-invasive pulmonary aspergillosis treated with voriconazole.
\end{abstract}

Keywords: Chronic necrotizing pulmonary aspergillosis; Hilum; Pneumonia; Aspergillosis

\section{Introduction}

Chronic necrotizing pulmonary aspergillosis (CNPA), also called semi-invasive pulmonary aspergillosis, was first described in the early 1980s as a distinct type of pulmonary aspergillosis [1]. CNPA is characterized by a pulmonary infiltration with cavitation in patients with chronic pulmonary disease, slight immunodeficiency or healthy patients [2]. Diagnosis is confirmed by pathological evidence of lung tissue invasion by the fungus. Clinical diagnosis by combined clinical, radiological and laboratory findings is needed because histopathological confirmation cannot always be obtained in the clinical setting [1]. There are a few reports in the literature that semiinvasive aspergillosis can occur in adults following radiotherapy $[3,4]$. In this report, we presented chronic necrotizing pulmonary aspergillosis in a patient with non-small cell lung carcinoma (NSCLC) following radiotherapy

\section{Case}

A 57-year-old man was admitted to our pulmonary outpatient clinic with a history of left side pleuritic chest pain, non-productive cough, fever and dyspnea for 3 days. He was diagnosed NSCLC nine months ago. He received chemotherapy and radiotherapy 5 months and 2 weeks ago, respectively. His physical examination was unremarkable. Blood sample analysis showed that he had no abnormalities except for an elevated erythrocyte sedimentation rate (ESR) $(60 \mathrm{~mm} / \mathrm{h})$ and $\mathrm{C}$ reactive protein $(\mathrm{CRP})(29.65 \mathrm{mg} / \mathrm{dL})$. His oxygen saturation was normal. Chest radiology revealed a cavitary lesion of middle and lower lung field (Figure 1) and on HRCT there was a $50 \times 37 \mathrm{~mm}$ solid mass lesion in the left hilum surrounding left upper bronchus (Figure 2) and $12 \times 8 \mathrm{~cm}$ cavitary lesion on the segments of the left lung lobe with air-liquid level (Figure 3 ).

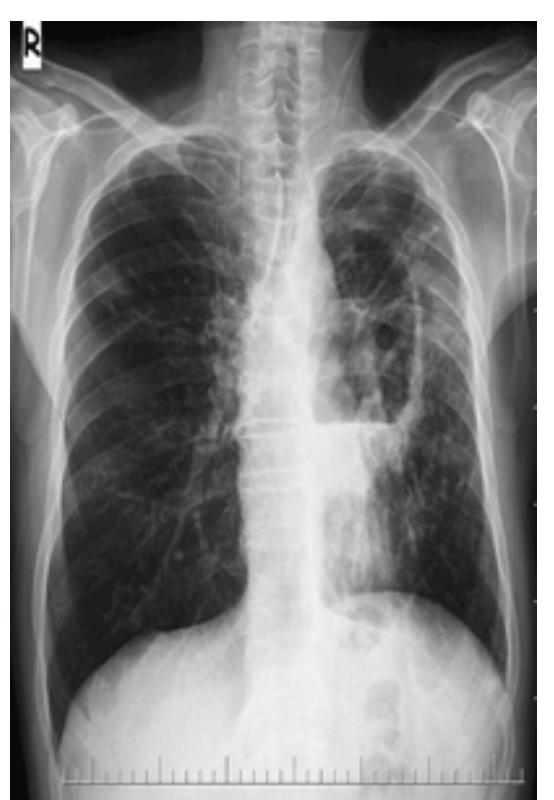

Figure 1: Cavitary lesion of left middle and lower lung field

He was used different therapy of antibiotics for a month but there was no clinical response to that treatment. Bronchoscopy was performed for bronchoalveolar lavage (BAL) fluid. Aspergillus fumigatus was found his mycological exams of BAL fluid. Galactomannan was positive in serum. Our final diagnosis was semiinvasive pulmonary aspergillosis and we started him on voriconazole (400 mg per day, orally).

\section{Discussion}

We have presented a rare but somehow neglected entity in clinical practice. Lung cancer, radiotherapy and aspergillosis are more rare 
coincidental presentation. To the best of our knowledge, semi-invasive aspergillosis was reported to occur in adults after radiotherapy $[3,4]$.

CPNA had been recognized as a different type of infection that does not fit into traditional categories. It runs a more indolent course, in occurring in patients with mildly impaired immunity as our patient [5]. The most common presentation is chronic productive cough. The second common presentation is hemoptysis, which varies from severe to trivial. The third is with only constitutional symptoms. Dyspnea is a common feature but usually reflects underlying lung disease unless CNPA is very distinctive. Chest pain is uncommon, but does occur [6]. Our patient was referred complaints of left side pleuritic chest pain, non-productive cough, fever, and dyspnea.

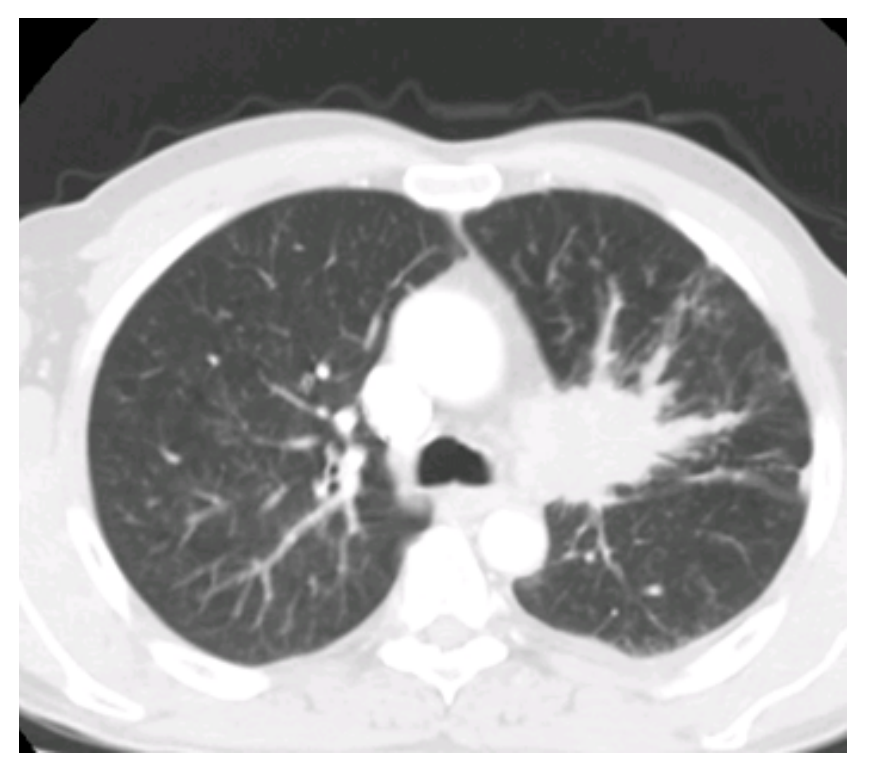

Figure 2: Mass lesion of left hilum

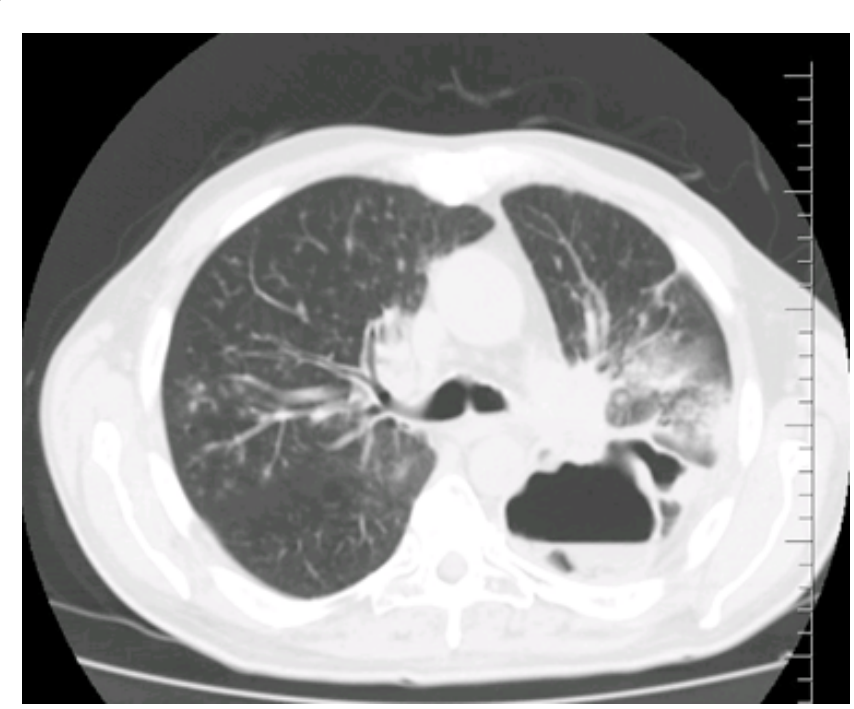

Figure 3: Cavitary lesion on the segments of the left lower lung lobe with air-liquid level
Bellamy et al. reported the cases of 2 patients who underwent lobectomy followed by irradiation for lung cancer and subsequently developed an aspergillus-infected cavity in the irradiated lung parenchyma. They speculated that it was far from certain that aspergillosis must always develop in a pre-existing cavity. In cases where it developed on post-radiotherapy lung lesions, their patients and a review of the literature incline them to believe that the fungus itself was responsible for the formation of cavities in lesions of radiation pneumonia [7].

The diagnosis of aspergillus infection is not always easy as it requires detection of Aspergillus in cultures and/or demonstration of tissue invasion by the fungus in the histological exam. In most cases, the diagnosis is made by tissue isolation through invasive methods. Serological tests are adjuncts to support or exclude the diagnosis in the appropriate clinical context but they do not make a definitive diagnosis [8]. We diagnosed our patient microbiologically and serologically.

All patients with CNPA exhibit radiological evidence of a cavitary lesion in the lung, usually in one or both upper lobes. Initially, infiltrates are ill-defined areas of consolidation or small cavities that progressed to form well-defined cavities. Cavities may be large or small. Over time, these cavities became multiple with thickened wall [6]. Namesaya et al. reported three middle-aged to older men autopsy cases of CNPA evaluated histopathologically. Radiologically, progressive upper lobe cavitary infiltrates were seen with mycetomas and infiltration in lower lung fields infection. The area of progressive infiltration revealed bacterial pneumonia, organizing pneumonia or organizing diffuse alveolar damage without aspergillus [1]. Our patient had a cavitary lesion on the segments of the left lung lobe with airliquid level and the thickness of cavity was $18 \mathrm{~mm}$.

Treatment is most often prolonged or combined. The choice of the anti-fungal was based on the normal immune status and non-severity of the infection, which allows for oral treatment $[8,9]$. The duration of symptom before the institution of therapy ranges from one month to greater than two years [10].

\section{Conclusion}

This is an original case report of interest to pulmonary and infectious disease specialties. To the best of our knowledge, there are a few reports in the literature that the fact that semi-invasive aspergillosis can occur following radiotherapy. We have paid attention that clinicians must aware of post-radiotherapy chronic necrotizing pulmonary aspergillosis in a patient with NSCLC.

\section{References}

1. Namesaya N, Tomioka H, Kaneda T, Kida Y, Kaneko M, et al. (2012) [Three autopsy cases of chronic necrotizing pulmonary aspergillosis]. Kansenshogaku Zasshi 86: 597-603.

2. Arévalo M, Solera J, Rodríguez F, Vizcaya M, Vercher R, et al. (1991) [Chronic necrotizing pulmonary aspergillosis caused by Aspergillus niger]. Med Clin (Barc) 97: 620-622.

3. Carbone PP, Nunnink JC (1984) Aspergillosis infection following radiotherapy. N Y State J Med 84: 434-435.

4. Le Tallec Y, Delaude A, Vadhat F, Moreau G (1966) ["Aspergilloma on the radiotherapeutic lung"]. J Fr Med Chir Thorac 20: 557-565.

5. Al-Alawi A, Ryan CF, Flint JD, Müller NL (2005) Aspergillus-related lung disease. Can Respir J 12: 377-387. 
Citation: Balbay EG, Bahar Y, Berik S, Annakkaya AN (2014) Chronic Necrotizing Pulmonary Aspergillosis in a Patient with Non-Small Cell Lung Carcinoma Following Radiotherapy. J Clin Case Rep 4: 358. doi:10.4172/2165-7920.1000358

Page 3 of 3

6. Denning DW (2001) Chronic forms of pulmonary aspergillosis. Clin Microbiol Infect 7 Suppl 2: 25-31.

7. Bellamy J, Broquie G, Leroy-Terquem E, Verdoux P (1989) [Aspergillosis and radiation-induced pneumonia. What relationship? Apropos of 2 cases]. Rev Pneumol Clin 45: 86-89.

8. Salgado SM, Costa CA, Bugalho AA, Semedo JA, Ribeiro JC, et al. (2010) Semi-invasive aspergillosis in an immunocompetent patient with SwyerJames-MacLeod Syndrome: a case report. J Med Case Rep 4: 153.
9. Sugar AM. Treatment of invasive aspergillosis. Uptodate. 2009.

10. Binder RE, Faling LJ, Pugatch RD, Mahasaen C, Snider GL (1982) Chronic necrotizing pulmonary aspergillosis: a discrete clinical entity. Medicine (Baltimore) 61: 109-124. 